$12-1-2006$

\title{
Perceived Source Credibility of Local Television News: The Impact of Television Form and Presence
}

\author{
Cheryl C. Bracken
}

Cleveland State University, c.bracken@csuohio.edu

Follow this and additional works at: https://engagedscholarship.csuohio.edu/clcom_facpub

Part of the Communication Commons

How does access to this work benefit you? Let us know!

\section{Publisher's Statement}

This is an Author's Accepted Manuscript of an article published in Journal of Broadcasting \& Electronic Media, 2006, available online: http://www.tandfonline.com/10.1207/ s15506878jobem5004_9.

\section{Recommended Citation}

Bracken, C. C. (2006). Perceived Source Credibility of Local Television News: The Impact of Television Form and Presence. Journal of Broadcasting \& Electronic Media, 50(4), 723-741. https://doi.org/ 10.1207/s15506878jobem5004_9

This Article is brought to you for free and open access by the School of Communication at EngagedScholarship@CSU. It has been accepted for inclusion in Communication Faculty Publications by an authorized administrator of EngagedScholarship@CSU. For more information, please contact library.es@csuohio.edu. 


\title{
Perceived Source Credibility of Local Television News: The Impact of Television Form and Presence
}

\section{Cheryl Campanella Bracken}

\begin{abstract}
An increasing number of local news stations are producing and broadcasting their newscasts in high-definition television (HDTV), but to date there has not been an investigation of audience perceptions of news in high definition. This study presents the results from an experiment investigating the influence of television form (image quality and field of view) on presence and audiences' perceptions of source credibility for news anchors and local news. The results demonstrate that improved image quality (HDTV) has a positive influence on audience perceptions of source credibility and the overall credibility of newscasts. Implications are discussed.
\end{abstract}

The perceptions audience members form regarding television news content has long been of interest to communication researchers. Perceptions of credibility have been found to be influenced by the content of the news reports (Austin \& Dong, 1994) and characteristics of the news anchor (Markham, 1968), suggesting that perceptions of credibility may be influenced by presentation variables. The use of high-definition (HD) television may be one such variable.

Recently, some local news stations have begun to broadcast their local news in $\mathrm{HD},{ }^{1}$ and there is evidence that audience viewing $\mathrm{HD}$ television programming is growing. The Consumer Electronics Association (CEA) reported record-breaking sales of HD-capable televisions in 2005, with 11.7 million units sold since 1998 (CEA, 2005). Although there is evidence that larger audiences are watching a growing number of programs, including local news, in HD, the research has lagged behind. It is important to understand audience perceptions of news (and in this study HD news), because such perceptions influence choices made by individual media users ranging from selection of news sources to how they interpret political candidates' positions. Although knowledge about how news content influences viewers' perceptions is vast (e.g., agenda setting and priming), relatively little is known about the role of television form in forming perceptions.

The concept of presence and credibility are linked in this article through the transportation imagery model (TIM). The TIM suggests that the use of narrative is more per- 
suasive than nonnarrative presentations. The TIM findings connect presence and credibility by presenting evidence that feelings of being part of the action can lead media users to see the message as more credible.

This exploratory study investigates the role of television form variables including image quality and image size on perceptions of credibility of the news anchors and overall newscast. The study also seeks to confirm prior findings regarding these form variables and audience members' sensations of presence (the perceptual illusion of nonmediation).

\section{Source Credibility}

Source credibility is the amount of credibility (believability) attributed to a source of information (either a medium or an individual) by the receivers. Source credibility of an individual has been widely studied by interpersonal communication scholars (e.g., Hamilton, 1998; Hovland \& Weiss, 1951 ; McCroskey, 1993). Within mass communication, the concept was originally studied as audiences' attitudes toward mass media sources of information (Hovland, Janis, \& Kelley, 1953). This conceptualization has been formalized by Gunther (1992), who argued that credibility is an audience response and not an attribute of the message source. He suggested that involvement is a better predictor of perceived credibility - "a person's involvement in situations, issues, or groups will show the greatest explanatory power" (p. 152). The study presented here has adapted Gunther's view of credibility as an attribute of the individual audience members.

\section{Source Credibility and Media News Sources}

Although the groundwork for studying credibility as an audience/individual characteristic has been examined, not all researchers agree with Gunther's conceptualization. Earlier credibility studies within mass communication frequently focused on how media audiences perceive the credibility of different media channels (e.g., Newhagen \& Nass, 1989; Sargent, 1965) and less frequently applied the concept to an individual as a source of information. Examples of studies comparing news credibility among media channels include comparing television to newspapers (McCroskey \& Jenson, 1981; Newhagen \& Nass, 1989; Sargent, 1965) and comparing the Internet to traditional news outlets (T. J. Johnson \& Kaye, 1998). Perceptions of the credibility of media sources have also been studied (Rouner, Slater, \& Buddenbaum, 1999). The general trend is that media audiences rate their primary source of news as being a credible source and that such ratings have recently been found to apply to Internet news sources (T. J. Johnson \& Kaye, 2004; Sundar, 1998). Although these findings are helpful in understanding how audiences perceive credibility among media channels, they do not address the unique contributions made by media form variables. 


\section{Source Credibility and Individuals in the Media}

Research examining the source credibility of people or characters appearing on television is scant and typically focuses on characteristics of the television journalists (Engstrom, 1994; E. Johnson, 1984). However, there is a precedent for studying source credibility of news anchors. In an experiment Markham (1968) examined the source credibility of television news anchors and found several distinct factors of credibility, including three that resemble those later confirmed by Berlo, Lemert, and Mertz (1969-1970). ${ }^{2}$ This study intends to extend these findings by including formal features as an independent variable.

\section{Source Credibility and Formal Features}

Some evidence suggests that formal features of television can impact viewers' perceptions of credibility. Reeves and Nass (1996) conducted an experiment exploring whether television audiences' perceptions of political candidates were influenced by the existence of cuts. ${ }^{3}$ The participants watched a series of political ads with or without cuts. The researchers found that participants who viewed the multiple cut ads rated the candidates as more favorable than those who watched the ads without cuts. In addition, they found "more cuts equaled more honesty, trust, intelligence, open mindedness, and sincerity" (p. 233).

Further support is provided by Bracken, Neuendorf, and Jeffres (2003), who conducted an experiment to study the influence of screen size on perceptions of credibility of the 2000 presidential candidates. The participants watched clips from presidential debates on either a small (20-inch) or large (120-inch) screen and then rated the credibility of each candidate. The results demonstrate that perceptions of source credibility were impacted by the size of the television screen size, with both the candidates being rated as more dangerous (less credible) on the larger screen. Taken together these two studies provide a foundation demonstrating that form of television can influence audience perceptions.

\section{Presence}

The term presence refers to a sense_-physical and mental—of being in a remote, mediated environment (Minsky, 1980). This is the current accepted definition of presence:

\footnotetext{
A psychological state or subjective perception in which even though part or all of an individual's current experience is generated by and/or filtered through human-made technology, part or all of the individual's perception fails to accurately acknowledge the role of the technology in the experience. (Lombard, 2000, II 2)
}

It should be noted that this perception does not represent a perceptual or psychological malfunction or psychosis, in which the mediated experience is consciously con- 
fused with what is nonmediated or "real," and it is generally accepted as a psychological state (Lee, 2004; Lombard \& Ditton, 1997; Wirth et al., in press). There is evidence that when asked, users of any current or likely future medium can accurately report that they are using and/or viewing a medium (Lombard \& Ditton, 1997). As a perceptual illusion, presence is a property of a person, and because it results from an interaction among form and content characteristics of a medium and characteristics of the media user, it can and does vary across individuals and across time for the same individual.

A large number of factors have been identified as potentially important to producing presence in media users. This study focuses on several form variables of television found to impact presence. Previous research in this area has demonstrated that larger images (Bocker \& Muhlbach, 1993; Heeter, 1992; Lombard, 1995; Lombard, Reich, Grabe, Bracken, \& Ditton, 2000; Zeltzer, 1992) and improved image quality (Bracken, 2005b; Neuman, 1990) led to stronger presence sensations. Another form variable relevant to newscast and likely to encourage a sense of presence is the use of direct address (Horton \& Wohl, 1956). This study manipulates both image size and image quality.

\section{Screen Size and Field of View}

A number of studies have explored the impact of screen size on media users' perceptions of content (see Grabe, Lombard, Reich, Bracken, \& Ditton, 1999, for a review). The findings are fairly consistent-larger screens and images lead to the audience perceiving the dependent variables to be greater (i.e., the movement was faster [Lombard et al., 2000]; larger images were more arousing [Reeves \& Nass, 1996]). The explanation provided in most of the studies is that larger images are psychologically processed as being "larger" (even though an image is not real). Reeves and Nass pointed out that larger images (larger screens) take up more of a person's peripheral vision. "This means that the boundary between the screen and the rest of the environment is farther in the corners of vision. This makes the boundary less noticeable" (Reeves \& Nass, 1996, p. 195). One way to manipulate these boundaries is to increase the screen size and measure how much of a person's peripheral vision focused on the screen is field of view (FOV).

\section{Presence and Formal Features}

Presence and Screen Size. Researchers have studied screen size as a form variable that, when increased (larger screen size), leads to more presence sensations. Consistent with the aforementioned explanation by Reeves and Nass, the increases in presence sensations have been attributed to the idea that larger images promote perceived realism of the content because larger images more closely resemble their real-world counterparts (Grabe et al., 1999).

Although there are numerous screen size studies, only a few of them incorporated elements of presence. Elements of presence incorporated into these studies by the re- 
searchers included items relating to realism of the content portrayed. Two early studies examined content displayed on large projections screens. Specifically, Hatada, Sakata, and Kusaka (1980) manipulated a number of presentation variables for participants who watched still images presented in a circular display. They varied display area (screen size from 20 to 85 inches $^{4}$ ) and viewing distance (screen size and viewing distance together can be used to calculate field of view). They found that participants reported a greater sensation of reality when viewing images on the large screen. Similarly, Neuman (1990) found that for higher resolution images, participants who watched images on large-screen (180-inch) displays reported higher levels of realism than those who watched on the smaller screen (35-inch).

The influence of four different consumer-controlled formal features-screen size (70-inch vs. 35-inch televisions), audio size (the number of active speakers), video fidelity, and audio fidelity —on viewers' perceptions were investigated (Reeves \& Nass, 1996). The participants watched scenes approximately 1 minute long from action adventure entertainment films. Participants who watched the clips on the large screen reported feeling as if they were part of the movie scene and rated the content as more realistic than those who watched the smaller screen.

A similar result was found by Lombard et al. (2000), who examined participants' presence responses to point-of-view movement camera technique (i.e., the viewers see the action through the eyes of the character or real-life participant). They found that participants who watched the larger screen television (46-inch) reported feeling a greater sense of movement than viewers who watched the scenes on a small-screen (12-inch) television.

In an experiment linking Burgoon's Nonverbal Expectancy Violations Model (Burgoon, 1978; Burgoon \& Hale, 1988; Burgoon \& Jones, 1976; Burgoon \& Walther, $1990)^{5}$ to mediated experiences, Lombard (1995) found that television audiences' responses to interpersonal distance cues (manipulated via image size and viewing distance) were similar to responses demonstrated in interpersonal communication studies. Participants who watched larger television screens (42- and 26-inch screens vs. a 10 -inch screen) reported more positive emotional responses, including higher levels of attraction to anchors on the screen. The results suggest that television viewers experience sensations of presence when viewing people in mediated environments (television) and that screen size plays a role in evoking these types of responses.

Taken together, the results of these studies demonstrate that image size can influence audience perceptions and suggest that additional research is necessary to better understand the phenomenon. However, most previous screen-size studies with some interest in presence have employed unique content (i.e., point of view, still photographs, or short clips taken from films). This study incorporates an intact local newscast to explore the role of screen size.

Presence and Image Quality. Another form variable shown to influence viewer sensations of presence is image quality. Initially, image quality was hypothesized as a form variable that might increase the sensations of presence experienced by media users (Lombard \& Ditton, 1997), which has been confirmed by more recent empirical evi- 
dence (Bracken, 2005b). In a study exploring television viewers' presence responses to varying image-quality levels, Bracken used HD and NTSC television images of varying scenic scenes to manipulate image quality. The improved image quality provided by $\mathrm{HD}$ led to increased levels of various dimensions of presence, including immersion, spatial presence, perceived realism, and social presence-passive dimensions of presence. The study presented here extends knowledge of presence by investigating if natural-occurring content can also induce a sense of presence in viewers.

\section{Presence and Source Credibility}

The link found between involvement and source credibility (Gunther, 1992) suggests that source credibility may also be influenced by audiences' sensations of presence or at least by the level of immersion they experience while viewing the program. It has been suggested that the more complex a stimulus, the more likely people are to be motivated to attend to the information (Berlyne, 1960). Because HD television images are more visually complex, with 1,080 lines per television screen versus the 480 lines available with standard definition (NTSC) television sets, it makes sense that HD images are likely to encourage viewer motivation and involvement and perhaps influence perceptions of source credibility.

These concepts can be linked by applying the TIM (Green \& Brock, 2000). TIM argues that media users are "transported" into the mediated world or that they feel drawn in to the story and that this sense of transportation results in the audience being more persuaded. Although TIM was developed within consumer psychology and originally applied audience responses to printed materials, Green and Brock suggested that TIM can be applied to other contents containing narratives. The mechanism for persuasion presented by Green and Brock is a separate route from dual-process models (i.e., Elaboration Likelihood Model [Petty \& Cacioppo, 1984] and heuristic and systematic processing [Chaiken, 1987]). The "transportation" of a media user into the narrative world discourages the argumentation that exists in the other attitude change models. TIM has recently been linked to the larger presence literature by Bracken (2005a), who claimed that the basic tenets of TIM and presence are the same-_both are interested in the phenomenon of media users feeling as if they are a part of the action or who have a sense of being there (in the story). The author believes that this linkage between presence and TIM is justified in the current context of news because many news stories are episodic (i.e., a news story presenting a single person's circumstances in a story format) rather than thematic (i.e., a news story presenting the general implications of an event or circumstance accompanied by evidence; lyengar, 1991) and this is particularly true of local newscasts - which is what was employed in the study presented here.

Based on this and evidence presented earlier in the article, the following hypotheses are posited:

$\mathrm{H}_{1}$ : Participants who view the newscast with a wider field of view (larger image) will report greater sensations of presence than those who view the same newscast in a narrower field of view. 
$\mathrm{H}_{2}$ : Participants who view the newscast in $\mathrm{HD}$ will report higher levels of presence than participants who view the same newscast in NTSC.

$\mathrm{H}_{3}$ : Participants who view the newscast in HD will rate the both (male and female) newscasters as more credible than those who view the same newscast in NTSC.

$\mathrm{H}_{4}$ : Participants who view the newscast with a wider field of view (larger image) will rate the newscast as more credible than those who view the same newscast in a narrower field of view.

$\mathrm{RQ}_{1}$ : Will the participants who view the newscast in $\mathrm{HD}$ rate the newscast as more credible?

Further, because improved image quality (Bracken, 2005b) and larger FOV (IJsselsteijn, de Ridder, Freeman, Avons, \& Bouwhuis, 2001) have been found in the past to increase the likelihood that participants will experience sensations of presence, the following research question is presented:

$\mathrm{RQ}_{2}$ : Will the participants who report experiencing sensations of presence rate the newscast as more credible?

\section{Method}

Two independent variables were manipulated, image quality (HDTV vs. NTSC) and field of view (range $\left.=14.8^{\circ}-53.1^{\circ}\right)$. Viewers $(N=140)$ watched a local newscast from another market. The experiment was between-subjects: One group of participants watched the newscast television in $\mathrm{HD}(n=70)$, and the other group watched the newscast in NTSC $(n=70)$. The participants viewed in four groups. The experiment received Institutional Review Board approval from a Midwestern university.

\section{Participants}

The participants were between 18 and 55 years of age $(M=21.8, M d n=20, S D=$ 4.88). Seventy-two $(51 \%)$ participants were female, and $64(49 \%)$ were male. The participants' reported racial identities were Caucasian $(60 \% ; n=84)$; African American $(27 \% ; n=38)$; and Asian, Hispanic, and other $(13 \% ; n=18)$. The participants were recruited from sections of a large introductory communication course, which has a research requirement.

\section{Stimulus}

A local newscast from a different media market was obtained from WRAL (Raleigh-Durham, NC). This particular station was selected because it was the only station broadcasting its local news in HD at the time the study was conducted. The newscast was shown in its entirety (including commercials) to increase the ecological validity of the study. The newscast contained two primary anchors (one female and 
one male). There were additional reporters, but the majority of the newscast was presented by the anchors. The newscast contained the standard elements of local news: a local segment, a short international segment, sports, and weather.

The out-of-market newscast provided the benefit of ensuring that the participants were not familiar with either of the news anchors or the events presented. The content of the newscast had a regional focus with very little entertainment news. The presentation of the stories was not sensationalized (for a detailed explanation of sensationalism and news, see Grabe, Zhou, \& Barnett, 2001).

\section{Procedure}

The participants entered a large auditorium and were randomly assigned to sit in either the front or the back of the room to correspond with the large and small field of view. After all the participants were seated, the experimenter explained that the participants would be viewing a newscast and that immediately following the program they would complete a questionnaire. The participants were asked to identify the seat they were sitting in by the row and seat number to allow for the calculation of FOV. The entire procedure took about 45 minutes.

\section{Independent Measures}

Image Quality. The image quality of the newscast was manipulated, with one group watching the newscast in HD and the other watching the newscast in NTSC.

FOV. The FOV was determined by how far the participants were sitting from the screen and the shape of the projected image. The participants viewed a 162-inch screen measured diagonally and saw the images in an FOV ranging from $14.8^{\circ}$ (narrow FOV) to $53.1^{\circ}$ (wide FOV; Collins, 2002). The actual distance that participants sat from the screen ranged from 14 to 55 feet.

\section{Dependent Measures}

The dependent measures were a variety of presence and credibility scales that were measured via a paper-and-pencil questionnaire.

\section{Presence}

The amount of presence experienced by the participants was measured using a multidimensional presence scale developed by Lombard and Ditton (2000) and previously used by Bracken and Atkin (2004) and Bracken (2005b). The presence dimensions included were social presence-active and social presence-passive, immersion, and parasocial interaction. 
Social Presence-Passive. Participants responded from 1 (not well) to 7 (very well) for four statements designed to measure the extent to which television viewers feel they were able to observe nonverbal cues in a mediated environment. The four statements were "During the media experience how well were you able to observe ... (1) the body language, (2) facial expressions, (3) changes in tone of voice, and (4) style of dress ... of the people you saw/heard?" Cronbach's alpha for the scale was .88 .

Immersion. Participants responded from 1 (not at all) to 7 (very much) for five statements based on a scale developed to measure the extent to which television viewers reported feeling immersed in the television environment. Example statements include "How involving was the media experience?" and "To what extent did you feel mentally immersed?" Cronbach's alpha for the scale was .76.

Perceptual Realism. Participants responded from 1 (not at all) to 7 (very much) for six statements intended to measure the extent to which television viewers feel a sense of realism when viewing television. The six statements included such questions as "How much did the things/people in the environment you saw/heard SOUND like they would if you experienced them directly?" "How much did the things/people in the environment you saw/heard LOOK like they would if you experienced them directly?" and "How much did you feel like the events you saw/heard were happening to you?" Cronbach's alpha for the scale was .85 .

Social Presence Actor Within Medium (Parasocial Interaction). Participants responded from 1 (never) to 7 (a/ways) for seven statements measuring the extent to which television viewers feel a sense of involvement with or connection to characters or television personalities when they watch television programs and movies. Examples of the statements include "How often did you have the sensation that people you saw/heard could also see/hear you?" "To what extent did you feel you could interact with the person you saw/heard?" "How often did it feel as if someone you saw/heard in the environment was talking directly to you?" and "How often did you want to or did you make eye contact with someone you saw/heard?" Cronbach's alpha for the scale was .81 .

\section{Source Credibility}

Participants responded to semantic differential scales for three dimensions: safety, dynamism, and qualification design by Berlo et al. (1969-1970). This particular source credibility scale divides the concept into three distinct dimensions. Participants evaluated each candidate separately for each of the three dimensions.

Safety. Participants responded from 1 (negative) to 7 (positive) for five semantic differential scales designed by Berlo et al. (1969-1970). The five items were "dishonest-honest," "cruel-kind," "dangerous-safe," "unfriendly-friendly," and "unjust- 
just." Cronbach's alpha for the scale was .90 for the female anchor and .94 for the male anchor.

Dynamism. Participants responded from 1 (negative) to 7 (positive) for four semantic differential scales designed by Berlo et al. (1969-1970). The four items were "meek-aggressive," "hesitant-emphatic," "timid-bold," and "passive-active." Cronbach's alpha for the scale was .72 for the female anchor and .77 for the male anchor.

Qualification. Participants responded from 1 (negative) to 7 (positive) for five semantic differential scales designed by Berlo et al. (1969-1970). The five items were "untrained-trained," "inexperienced-experienced," "unqualified-qualified," "unskilledskilled," and "uninformed-informed." Cronbach's alpha for the scale was .93 for the female anchor and .95 for the male anchor.

\section{Overall Newscast Credibility}

Participants responded from 1 (negative) to 7 (positive) for 11 semantic differential scales designed by Gaziano and McGrath (1986). Examples of the 11 items include "unfair-fair," "biased-unbiased," "invades people's privacy/respects people's privacy," and "has well-trained reporters/has poorly trained reporters." Cronbach's alpha for the additive scale was .73 .

\section{Analysis and Results}

A series of two-way analyses of variance with the independent variables image quality (HD or NTSC) and FOV were used to test the hypotheses and RQ1. The specific results are presented in Tables 1 to 3.

$\mathrm{H}_{1}$, predicting viewers who watched the newscast with a wider FOV would report greater levels of presence sensations, was not supported across all of the presence variables. The participants did not report experiencing presence sensation when viewing the wider FOV (larger images) as opposed to when they viewing from a narrower FOV (smaller images; see Table 1).

Some support was found for $\mathrm{H}_{2}$, which predicted that participants who viewed the newscast in HD would report higher levels of presence than participants who viewed the same newscast in NTSC (see Table 1). The main effects were significant for two of the four presence dimensions tested. Specifically, viewers of HD reported a higher level of social presence-passive (the ability of television viewers to see nonverbal cues; $M=4.83, S D=1.42)$ than those who watched the same newscast in NTSC $(M=$ $4.19, S D=1.71)$. Higher levels of immersion were also reported by viewers who watched the newscast in $\mathrm{HD}(M=4.02, S D=1.45)$ than by viewers of the NTSC newscast $(M=3.40, S D=1.22)$. In addition, the interaction between image quality and FOV was significant for the social presence with an actor in a medium dimension (parasocial interaction), with participants who watched in HD with a wider FOV re- 
Table 1

Analysis of Variance Table: Image Quality and FOV for Presence Dimensions

\begin{tabular}{|c|c|c|c|c|c|}
\hline Source of Variation & SS & $d f$ & MS & $F$ & $\eta^{2}$ \\
\hline \multicolumn{6}{|l|}{ Social presence-passive } \\
\hline \multicolumn{6}{|l|}{ Main effects } \\
\hline Image quality & 13.39 & 1 & 13.39 & $5.68^{*}$ & .05 \\
\hline FOV & 40.82 & 13 & 40.82 & 1.32 & .13 \\
\hline \multicolumn{6}{|l|}{ Two-way interactions } \\
\hline Image Quality x FOV & 17.59 & 11 & 1.56 & 0.67 & .06 \\
\hline \multicolumn{6}{|l|}{ Immersion } \\
\hline \multicolumn{6}{|l|}{ Main effects } \\
\hline Image quality & 7.17 & 1 & 7.17 & $4.35^{*}$ & .04 \\
\hline FOV & 9.64 & 13 & 0.74 & 0.45 & .05 \\
\hline \multicolumn{6}{|l|}{ Two-way interactions } \\
\hline Image Quality × FOV & 28.62 & 11 & 2.60 & 1.56 & .14 \\
\hline \multicolumn{6}{|l|}{ Perceptual realism } \\
\hline \multicolumn{6}{|l|}{ Main effects } \\
\hline Image quality & 1.23 & 1 & 1.23 & 0.70 & .006 \\
\hline FOV & 15.73 & 13 & 1.21 & 0.69 & .08 \\
\hline \multicolumn{6}{|l|}{ Two-way interactions } \\
\hline Image Quality x FOV & 21.03 & 11 & 1.91 & 1.09 & .10 \\
\hline \multicolumn{6}{|c|}{ Social presence with actor in a medium } \\
\hline \multicolumn{6}{|c|}{ Main effects } \\
\hline Image quality & 2.48 & 1 & 2.48 & 1.74 & .02 \\
\hline FOV & 22.90 & 13 & 1.76 & 1.24 & .13 \\
\hline \multicolumn{6}{|l|}{ Two-way interactions } \\
\hline Image Quality x FOV & 29.33 & 11 & 2.67 & $1.87^{*}$ & .16 \\
\hline
\end{tabular}

Note: FOV = field of view.

$* p<.05$.

porting a stronger sense of parasocial interaction $(M=4.25, S D=2.45)$ than participants who viewed the newscast in NTSC with a smaller FOV $(M=1.93, S D=.62)$.

The results provide evidence that support $\mathrm{H}_{3}$, which stated that participants who watched the newscast in HD would rate the news anchors (both female and male) as being more credible than viewers who watched the NTSC version (see Table 2-3). Viewers of the HD version of the newscast rated each newscaster higher (more credible) in all three dimensions of source credibility. Specifically, the main effect for image quality was significant, with both anchors being rated as safer when seen in HD (female $M=5.57, S D=1.02$; male $M=5.48, S D=1.09$ ) than in NTSC (female $M=$ 4.76, $S D=1.06$; male $M=4.68, S D=1.14$ ). Similarly, the other dimensions were significant for the main effect. Participants rated each anchor as more dynamic when seen in $\mathrm{HD}$ (female $M=4.90, S D=1.00$; male $M=4.91, S D=1.03$ ) than when seen in NTSC (female $M=4.57, S D=1.11$; male $M=4.59, S D=.97$ ) and as more qualified 
Table 2

Analysis of Variance Table: Image Quality and FOV for the Female Anchor

\begin{tabular}{|c|c|c|c|c|c|}
\hline Source of Variation & SS & $d f$ & MS & $F$ & $\eta^{2}$ \\
\hline \multicolumn{6}{|l|}{ Safety } \\
\hline \multicolumn{6}{|l|}{ Main effects } \\
\hline Image quality & 18.33 & 1 & 18.33 & $16.34^{* *}$ & .13 \\
\hline FOV & 17.29 & 13 & 1.33 & 0.23 & .12 \\
\hline \multicolumn{6}{|l|}{ Two-way interactions } \\
\hline Image Quality x FOV & 6.68 & 11 & 0.61 & 0.54 & .05 \\
\hline \multicolumn{6}{|l|}{ Dynamism } \\
\hline \multicolumn{6}{|l|}{ Main effects } \\
\hline Image quality & 4.58 & 1 & 4.58 & $4.06^{*}$ & .05 \\
\hline FOV & 10.09 & 13 & 0.78 & 0.69 & .04 \\
\hline \multicolumn{6}{|l|}{ Two-way interactions } \\
\hline Image Quality x FOV & 13.77 & 11 & 1.25 & 1.11 & .10 \\
\hline \multicolumn{6}{|l|}{ Qualification } \\
\hline \multicolumn{6}{|l|}{ Main effects } \\
\hline Image quality & 8.07 & 1 & 8.07 & $4.29 *$ & .04 \\
\hline FOV & 18.34 & 13 & 1.41 & 0.75 & .08 \\
\hline \multicolumn{6}{|l|}{ Two-way interactions } \\
\hline Image Quality x FOV & 16.70 & 11 & 1.52 & 0.81 & .08 \\
\hline
\end{tabular}

Note: FOV $=$ field of view.

${ }^{*} p<.05 .{ }^{* *} p<.001$.

when seen in the HD version of the newscast (female $M=5.57, S D=1.29$; male $M=$ $5.60, S D=1.23$ ) than in the NTSC version (female $M=4.97, S D=1.40$; male $M=$ $5.14, S D=1.27$ ).

The results for $\mathrm{H}_{4}$ and $\mathrm{RQ}_{1}$, which inquire about the effect of viewing the newscast with a wider FOV and in $\mathrm{HD}$, has on perceived credibility of the overall newscast displayed a similar trend as seen previously in $\mathrm{H}_{1}$ to $\mathrm{H}_{3}$. Specifically, participants who watched the newscast with a wider FOV (the image took up more of their peripheral vision) did not rate the newscast as significantly more credible than the participants who viewed with a narrower FOV. There was a main effect for image quality, $F(1)=$ 6.45, $p=.001, \eta^{2}=.06$, with participants who viewed the newscast in $\mathrm{HD}$ rating the overall newscast as more credible $(M=4.74, S D=.95)$ than the participants who viewed the newscast in NTSC $(M=4.31, S D=.73)$. The main effect for $F O V, F(13)=$ $.82, p=.64, \eta^{2}=.09$, and the two-way interaction, $F(11)=1.23, p=.24, \eta^{2}=.12$, were not significant. Therefore, FOV did not play a role in how the audience members perceived the overall credibility of the newscast, whereas enhanced image quality (HD) improves the credibility rating of the overall newscast.

$R Q_{2}$, asking whether presence would influence audience members' perceptions of newscast credibility, was tested using forced entry multiple regression. Overall newscast credibility was the dependent variable, and the independent variables were the 
Table 3

Analysis of Variance Table: Image Quality and FOV for the Male Anchor

\begin{tabular}{|c|c|c|c|c|c|}
\hline Source of Variation & SS & $d f$ & MS & $F$ & $\eta^{2}$ \\
\hline \multicolumn{6}{|l|}{ Safety } \\
\hline \multicolumn{6}{|l|}{ Main effects } \\
\hline Image quality & 17.98 & 1 & 17.98 & $13.65^{*}$ & .11 \\
\hline FOV & 13.68 & 13 & 1.05 & 0.80 & .09 \\
\hline \multicolumn{6}{|l|}{ Two-way interactions } \\
\hline Image Quality x FOV & 7.46 & 11 & 0.68 & 0.52 & .05 \\
\hline \multicolumn{6}{|l|}{ Dynamism } \\
\hline \multicolumn{6}{|l|}{ Main effects } \\
\hline Image quality & 3.90 & 1 & 3.90 & $3.94 *$ & .04 \\
\hline FOV & 15.10 & 13 & 1.16 & 1.18 & .12 \\
\hline \multicolumn{6}{|l|}{ Two-way interactions } \\
\hline Image Quality x FOV & 11.90 & 11 & 1.08 & 1.09 & .10 \\
\hline \multicolumn{6}{|l|}{ Qualification } \\
\hline \multicolumn{6}{|l|}{ Main effects } \\
\hline Image quality & 6.19 & 1 & 6.19 & $3.86^{*}$ & .03 \\
\hline FOV & 17.81 & 13 & 1.37 & 0.85 & .09 \\
\hline \multicolumn{6}{|l|}{ Two-way interactions } \\
\hline Image Quality x FOV & 11.96 & 11 & 1.09 & 0.68 & .06 \\
\hline
\end{tabular}

Note: FOV $=$ field of view.

$* p<.05$.

presence dimensions (social presence-passive, immersion, perceptual realism, and social presence with actor in a medium [parasocial relationship]). The regression analysis revealed that the model significantly predicted perceptions of overall news credibility, $F(4,131)=6.76, p=.001, R^{2}=.17$. Immersion was the only significant predictor $(\beta=.297, p=.003)$ with participants who reported higher levels of immersions perceiving the newscast as more credible. The results demonstrate that immersion was a significant predictor and perceptual realism was approaching significance. For both presence dimensions, experiencing higher levels was a predictor of perceiving the newscast as more credible. This analysis presents evidence that some presence dimensions can influence audiences' perceptions of newscast credibility.

\section{Discussion}

Overall these results provide evidence that image quality as a form variablecan influence television audiences' perceptions, in general, and specifically affect perceptions of credibility supporting the findings by Reeves and Nass (1996) and Bracken et al. (2003). This study also offers additional support for previous findings (Bracken, 2005b) that increased image quality (HD) leads television viewers to experience a greater level 
of presence than the current NTSC standard television images. Further, sensations of presence were found to have a positive influence on ratings of credibility.

\section{Perception of Source Credibility}

One of the most important findings of this study is that perceptions of credibility can be influenced by the formal features of television. This suggests that credibility is not just an inherent quality of the source or person delivering a message. Specifically, the perception of the female and male anchors and the overall newscast as more credible in the HD condition demonstrates that image quality is a form variable worth consideration beyond the previous experiments on presence. The participants' rating of each of the main news anchors as being more credible than the same news anchors in NTSC has a larger implication for the upcoming conversion to HD. It is interesting that increased image quality led to increased credibility ratings for each of the news anchors. This is especially important, as image quality was the only difference between the two versions of the newscast as the use of wide-screen images was maintained in the standard (NTSC) version. These results may have far-reaching implications for other types of content as well (i.e., will reality programming be seen as more "real"?).

Recently there have been various discussions about who looks good (or terrible) in HD (Teitell, 2005). Although there has been a discussion about how HD can reveal imperfections in actors and performers, these findings suggest that improved image quality can also improve audience perceptions of characters and personalities, but as recent discussion suggests, not when there is visible acne or scars. These results seem to suggest that the characteristics of the news anchors themselves are in part responsible for audience perceptions of credibility, which supports the findings by Markham (1968) offering some reassurance for mature news anchors.

The results seem to support Gunther's (1992) argument that involvement is a predictor of credibility as immersion was the most powerful predictor of favorable credibility ratings. This is consistent with the TIM (Green \& Brock, 2000). Further, the results of this study ask the question, if television audiences are currently skeptical of television news today (Tsfati, 2003), will they continue to be after the HD conversion? Perhaps news viewing will increase because, as Tsfati and Cappella (2003) reported, skepticism of the media is related to the likelihood of viewing less news. Following this logic, if audiences perceive newscasts as more credible, then perhaps news viewing will increase. This also has implications for the ever-increasing sensational local news.

There was no support for hypotheses predicting higher levels of perceptual realism and social presence with actor in a medium (parasocial) would be reported by participants who saw the HD version of the newscast. The lack of parasocial results may be attributed to that selection of an out-of-town newscast (to avoid existing prejudices). It is unlikely the one exposure would allow time for the participants to feel connected to the news anchors; however, the interaction of HD and larger FOV was powerful. The lack of results for perceptual realism is more difficult to explain. Earlier findings by Bracken (2005b) suggested that even real-world content can be perceived as more 
real in HD, but the content in that study was not news. These results may be explained by earlier findings of perceived reality judgments being influenced by the origination of the story. People who saw stories from unfamiliar locations (in this study the newscast was from out of state) reported the stories as being more real than stories from locations the participants knew (Shapiro \& Chock, 2004).

\section{Presence and Formal Features}

The results are consistent with previous research on presence and image quality (Bracken, 2005b). The participants reported greater levels of immersion and social presence-passive (i.e., the ability to observe social cues). These results are important because the content used in this study was local news from a different market and did not contain stories to which the audience would have been previously exposed, suggesting that at least for this study immersion is not always equated with involvement, as suggested by Klimmt and Voderer (2003). It is surprising that there was a significant interaction between image quality and FOV for the parasocial dimension because this was the first exposure to the anchors for the participants. This particular result implies that television form is a very powerful part of the experience of television viewing and can impact perceptions to the level that individuals feel closer to people they have never even seen before.

The finding that audience members who reported feeling more immersed also rated the newscast as more credible contributes to the understanding of how experiencing a sense of presence impacts other traditional media effects. The author acknowledges that the other dimensions did not impact perceptions of credibility. Nevertheless, there is a growing number of studies demonstrating that presence plays a mediating role with third-person perception (Botta \& Bracken, 2003), body image disturbance (Botta \& Bracken, 2002), and persuasion (Kim \& Biocca, 1997). This trend suggests the presence may be a missing element in understanding how audience members a re affected by media content (and form) and deserves more attention in media effects studies.

However, the hypotheses and research questions about FOV did not support previous findings related to screen size (IJsselsteijn et al., 2001; Lombard et al., 2000). The increased FOV neither lead to higher levels of presence being experienced nor seemed to have an effect on the audiences' perceptions, contrary to previous screen size studies (with the exception discussed previously). At least for this particular content, it seems that regardless of the size of or the distance audiences sit from a HDTV set, the image quality has the most influence on their perceptions of media content. It may be that the FOV manipulation was not strong enough (i.e., there should have been a greater difference both closer and farther seating from the screen). It may also be that, for this particular type of content, FOV was not important in the audience's decision process.

Several areas of future research can be pursued based on the current results. First, the continued examination of determinants of presence and television is an area that needs additional evidence to support these and earlier findings regarding form vari- 
ables and media users' experiences of presence. Second, the influence of improved image quality (HDTV) on audience perceptions needs to be investigated further. Third, the question of whether improved image quality can lead television audiences to perceive sensational newscasts as being credible or as more sensational needs to be answered. Fourth, characteristics of news programming should be isolated and studied (i.e., specific presenter characteristics, such as race and age). Last, there appears to be a trend throughout several studies, with content seen in HDTV being rated more positively than the same content seen in NTSC (e.g., see Botta \& Bracken, 2002). This trend suggests that improved image quality may impact television audiences' perceptions, including a character's physical attractiveness, reality judgments, and impact of message on oneself.

The author acknowledges that the results of this study may have been influenced by the design of the study, specifically, the group administration of the experiment may be responsible for the nonsignificant findings regarding the FOV hypotheses. Most screen-size studies employ individual administration, and each participant watches either a small- or large-screen television. In this study, the participants viewed a large projected image in a theater setting. In defense of the group administration, many people do view television in groups, with either their families or friends. Although the FOV (narrow and wide) are comparable to the FOV seen in other screen-size studies, it may be that the projected image or the setting was seen as different by the participants than watching a television set. The number of HD compatible projectors sold for home use has grown beyond expected sales in the past year (CEA, 2004).

In conclusion, the results of this study provide additional evidence that improved image quality contributes to television audiences' sense of presence. The results demonstrate that HDTV improves the credibility attributed to both news anchors and to the overall newscast. The implications of this finding suggest that the conversion to HDTV may influence television audiences' perceptions and viewing habits of news.

\section{Notes}

I There are currently 24 local television stations broadcasting in HD out of 772 local news stations in the United States.

2Berlo et al. (1969-1970) found three factors: safety, dynamism, and qualification.

${ }^{3} \mathrm{~A}$ cut is a transition between shots in which there is no overlap between images-a sudden transition (Lombard, Bracken, Snyder-Duch, \& Ditton, 2002).

${ }^{4} \mathrm{All}$ televisions screens are measured diagonally.

${ }^{5}$ The nonverbal expectancy model predicts that persons who violate expectations (e.g., more or less eye contact) will elicit arousal and cause an increase in attention.

\section{References}

Austin, E. W., \& Dong, Q. (1994). Source versus content effects on judgments of news believability. Journalism Quarterly, 71, 973.

Berlo, D. K., Lemert, J. B., \& Mertz, R. J. (1969-1970). Dimensions for evaluating the acceptability of message sources. Public Opinion Quarterly, 33, 563-576. 
Berlyne, D. E. (1960). Conflict, arousal, and curiosity. New York: McGraw-Hill.

Bocker, M., \& Muhlbach, L. (1993). Communicative presence in videocommunications. Proceedings of the Human Factors and Ergonomics Society 37th Annual Meeting, 37, 249-253.

Botta, R. A., \& Bracken, C. C. (2002, November). Muscle bound: Men, muscularity, and social comparisons. Paper presented to the Mass Communication division of the annual meeting of the National Communication Association, New Orleans, LA.

Botta, R. A., \& Bracken, C. C. (2003, May). Presence the equalizer: Reducing the third-person perception. Paper presented to the Mass Communication Division at the annual conference of the International Communication Association, San Diego, CA.

Bracken, C. C. (2005a). Are we persuaded by feeling "part of the action"? Exploring the similarities between the transportation imagery model and presence. Proceedings of the Eighth Annual International Meeting of the Presence Workshop, 8, 125-129.

Bracken, C. C. (2005b). Presence and image quality: The case of high definition television. Media Psychology, 7, 191-205.

Bracken, C. C., \& Atkin, D. (2004). A survey of presence evoking technology in our living room. Visual Communication Quarterly, 11(1-2), 23-27.

Bracken, C. C., Neuendorf, K. A., \& Jeffres, L. W. (2003, August). Screen size, source credibility, and presence: Audience reactions to the televised 2000 presidential debates. Paper presented to the Communication Theory and Methodology Division at the annual conference of the Association for Education in Journalism and Mass Communication, Kansas City, MO.

Burgoon, J. K. (1978). Attributes of the newscaster's voice as predictors of his credibility. Journalism Quarterly, 55, 276-281.

Burgoon, J. K., \& Hale, J. L. (1988). Nonverbal expectancy violations model: Elaboration and application to immediacy behaviors. Communication Monographs, 55, 58-79.

Burgoon, J. K., \& Jones, S. B. (1976). Toward a theory of personal space expectations and their violations. Human Communication Research, 2, 131-146.

Burgoon, J. K., \& Walther, J. B. (1990). Nonverbal expectancies and the evaluative consequences of violations. Human Communication Research, 17, 232-265.

Chaiken, S. (1987). The heuristic model of persuasion. In M. P. Zanna, J. M. Olson, \& C. P. Herman (Eds.), Social influence: The Ontario symposium (Vol. 5, pp. 3-39). Hillsdale, NJ: Lawrence Erlbaum Associates, Inc.

Collins, C. M. (2002). Viewing distance calculator. Retrieved March 23, 2005, from http:// www.myhometheater.homestead.com/viewingdistancecalculator.html

Consumer Electronics Association. (2004). Digital America: Home theater video. Retrieved March, 24, 2005, from http://www.ce.org/publications/books_references/digital_america/ home_theater/home_theater_video.asp

Consumer Electronics Association. (2005, January 18). Super Bowl XXXIX boosts digital television sales: Strong December sales close out record year. Retrieved March 24, 2005, from http://www.ce.org/press_room/press_release_detail.asp?id=10681

Engstrom, E. (1994). Effects of nonfluencies on speaker's credibility in newscast settings. Perceptual and Motor Skills, 78, 739-743.

Gaziano, C., \& McGrath, K. (1986). Measuring the concept of credibility. Journalism Quarterly, $63,451-462$.

Grabe, M. E., Lombard, M., Reich, R. D., Bracken, C. C., \& Ditton, T. B. (1999). Screen size and viewer responses to television: Research findings. Visual Communication Quarterly, 6(2), 4-9.

Grabe, M. E., Zhou, S., Barnett, B. (2001). Explicating sensationalism in television news: Content and the bells and whistles of form. Journal of Broadcasting \& Electronic Media, 45, $635-656$.

Green, M. C., \& Brock, T. C. (2000). The Role of Transportation in the Persuasiveness of Public Narratives. Journal of Personality \& Social Psychology, 79, 701-721.

Gunther, A. C. (1992). Biased press or biased public: Attitude toward media coverage of social-groups. Public Opinion Quarterly, 56, 147-167.

Hamilton, M. A. (1998). Message variables that mediate and moderate the effects of equivocal language on source credibility. Journal of Language and Social Psychology, 17, 109-143. 
Hatada, T., Sakata, H., \& Kusaka, H. (1980). Psychophysical analysis of the "sensation of reality" induced by a visual wide-field display. SMPTE Journal, 89, 560-569.

Heeter, C. (1992). Being there: The subjective experience of presence. Presence, 1, 262-271.

Horton, D., \& Wohl, R. R. (1956). Mass communication and para-social interaction: Observations on intimacy at a distance. Psychiatry, 19, 215-229.

Hovland, C. I., Janis, I. L, \& Kelley, H. H. (1953). Communication and persuasion. New Haven, CT: Yale University Press.

Hovland, C. I., \& Weiss, W. (1951). The influence of source credibility on communication effectiveness. Public Opinion Quarterly, 15, 635-650.

Ijsselsteijn, W., de Ridder, H., Freeman, J., Avons, S. E., \& Bouwhuis, D. (2001). Effects of stereoscopic presentation, image motion, and screen size on subjective and objective corroborative measures of presence. Presence: Teleoperators \& Virtual Environments, 10, 298-312.

Johnson, E. (1984). Credibility of Black and White newscasters to a Black audience. Journal of Broadcasting, 28, 365-386.

Johnson, T. J., \& Kaye, B. K. (1998). Cruising is believing? Comparing Internet and traditional sources on media credibility measures. Journalism and Mass Communication Quarterly, 75, $325-340$.

Johnson. T. J., \& Kaye, B. K. (2004). For whom the Web toils: How Internet experience predicts Web reliability and credibility. Atlantic Journal of Communication, 12, 19-45.

Kim, T., \& Biocca, F. (1997). Telepresence via television: Two dimensions of telepresence may have different connections to memory and persuasion. [Electronic version]. Journal of Computer-Mediated Communication, 3(2). Retrieved March 24, 2005, from http://jcmc.indiana .edu $/ \mathrm{vol} 3 /$ issue $2 / \mathrm{kim} \cdot \mathrm{html}$

Klimmt, C., \& Voderer, P. (2003). Media Psychology "is not yet there": Introducing theories on media entertainment to the presence debate. Presence: Teleoperators \& Virtual Environments, 12, 346-360.

Lee, K. M. (2004). Presence, explicated. Communication Theory, 14, 27-50.

Lombard, M. (1995). Direct responses to people on the screen: Television and personal space. Communication Research, 22, 288-324.

Lombard, M. (2000). The concept of presence: Explication statement. Available from International Society for Presence Research Web site: http://www.temple.edu/ispr/index.htm

Lombard, M., Bracken, C. C., Snyder-Duch, J., \& Ditton, T. B. (with Kaynak, M. S., \& Linder, J.) (2002). Structural features content analysis project coding manual. Retrieved April 30, 2002, from http://academic.csuohio.edu/kneuendorf/content/hcoding/lombardcb2.htm

Lombard, M., \& Ditton, T. B. (1997). At the heart of it all: The concept of presence. [Electronic version]. Journal of Computer-Mediated Communication, 3(2). Retrieved April 30, 2002, from http://jcmc.indiana.edu/vol3/issue2/lombard.html

Lombard, M., \& Ditton, T. B. (2000, March). Measuring presence: A literature-based approach to the development of a standardized paper-and-pencil instrument. Proceedings of the Third International Workshop on Presence. Retrieved March 24, 2005, from http://www.temple .edu/ispr/prev_conferences/proceedings/98-99-2000/2000/lombard.html

Lombard, M., Reich, R. D., Grabe, M. E., Bracken, C. C., \& Ditton, T. B. (2000). Presence and television: The role of screen size. Human Communication Research, 26(1), 75-98.

Markham, D. (1968). The dimensions of source credibility of television newscasters. Journal of Communication, 18,57-64.

McCroskey, J. C. (1993). An introduction to rhetorical communication (6th ed.). Englewood, NJ: Prentice Hall.

McCroskey, J. C., \& Jenson, T. A. (1981). Image of mass media news sources. Journal of Broadcasting, 19, 169-180.

Minsky, M. (1980, June). Telepresence. Omni, pp. 45-51.

Neuman, W. R. (1990, July). Beyond HDTV: Exploring subjective responses to very high definition television [Research report for GTE Labs and the TVOT Consortium]. Cambridge, MA: MIT Press.

Newhagen, J., \& Nass, C. (1989). Differential criteria for evaluating credibility of newspapers and TV-news. Journalism Quarterly, 66, 277-284. 
Petty, R. E., \& Cacioppo, J. T. (1984). The effects of involvement on responses to argument quantity and quality: Central and peripheral routes to persuasion. Journal of Personality and Social Psychology, 46, 63-81.

Reeves, B., \& Nass, C. (1996). The Media equation: How people treat computers, television, and new media like real people and places. Stanford, CA: CSLI Publications.

Rouner, D., Slater, M. D., \& Buddenbaum, J. M. (1999). How perceptions of news bias in news sources relate to beliefs about media bias. Newspaper Research Journal, 20(4), 41-51.

Sargent, L. (1965). The dimension of source credibility. Journalism Quarterly, 42, 35-42.

Shapiro, M. A., \& Chock, T. M. (2004). Media dependency and perceived reality of fiction and news. Journal of Broadcasting \& Electronic Media, 48, 675-695.

Sundar, S. S. (1998). Effort of source attribution on perception of online news. Journalism \& Mass Communication Quarterly, 75, 55-68.

Teitell, B. (2005). TV: Lights, camera, acne! Boston Herald, p. 52.

Tsfati, Y. (2003). Media skepticism and climate of opinion perception. International journal of Public Opinion Research, 15, 65-82.

Tsfati Y., \& Cappella, J. N. (2003). Do people watch what they do not trust? Exploring the association between news media skepticism and exposure. Communication Research, 30, 504-529.

Wirth, W., Hartmann, T., Boecking, S., Vorderer, P., Klimmt, C., Schramm, H., et al. (in press). A process model of the formation of spatial presence experiences. Media Psychology.

Zeltzer, D. (1992). Autonomy, interaction, and presence. Presence, 1, 127-132.

\section{Post-print standardized by MSL Academic Endeavors, the imprint of the Michael Schwarts Library at Cleveland State University, 2017}

